\title{
Evaluation of Mechanical Properties of a New Warm-Mix Asphalt using Sylvaroad Additive
}

\author{
By Dai Xuan $\mathrm{Lu}^{*}$ \\ Mofreh Saleh
}

Warm mix asphalts (WMA) have been gradually becoming more popular in the roading industry owing to their benefits compared to traditional hot mix asphalts (HMA), such as lower energy consumption and lesser emissions. In this paper, the authors investigated the performance of two WMA mixtures, using Evotherm and Sylvaroad, and compared them with HMA. The experimental investigation includes moisture susceptibility, fatigue cracking, rutting resistance, and a semicircular bending test. The results showed that HMA displayed the highest resistance to rutting, followed by the Evotherm mixture. The sylvaroad mixture showed the highest resistance to fatigue failure. However, only Evotherm mixture in this study passed the moisture susceptibility test, with a tensile strength ratio (TSR) of 91\%. Both HMA and Sylvaroad mixtures showed considerable stripping, with the most severe case belonged to Sylvaroad mixture. HMA showed the best in fracture resistance and a semi-circular bending test yielded tensile strength results in a similar trend with the indirect tensile strength method.

Keywords: Evotherm, Hot mix asphalt, Semi-circular, Sylvaroad, Warm mix asphalt.

\section{Introduction}

Warm mix asphalts (WMA) are emerging technologies, which has become-an interesting and important topic among researchers and practitioners. The WMA technologies are promising in bringing numerous benefits to the society. Especially, in the period when global warming and climate change become worldwide issues, the use of WMA becomes a priority. The main aim of WMA technologies is to reduce producing temperatures while still keeping a comparable to or better performance than HMA.

WMA technologies can be classified into three categories, including a foaming process, using organic additives, and using chemical additives (Zhang, 2010; Leng et al., 2013). Foaming technologies are mainly to introduce a small amount of water, by injecting it directly into a hot binder or into a mixing chamber (Larsen, 2001). At elevated temperatures, water evaporates and the steam is trapped in the binder, making the binder's volume significantly increase and reduce the viscosity of the binder, improving greatly the workability of mixtures

\footnotetext{
${ }^{*}$ University of Transport in HCMC, Vietnam.

* Associate Professor, University of Canterbury, New Zealand.
} 
and aggregate coating. Organic additives are products from wax, which are solid at ambient temperatures and generally start to melt at around $100^{\circ} \mathrm{C}$ (Zaumanis, 2010). During mixing and compacting at higher temperatures than the melting point, the organic additives reduce the viscosity of binder in the asphalt mixture (Capitão et al., 2012). When the asphalt mixture cools, the wax uniformly distributes and stiffens the binder (Rubio et al., 2012), which increases the resistance against permanent deformation. Chemical additives are normally a combination of anti-striping agents, emulsification agents and surfactants to improve coating, adhesion and the compatibility of the mixture. Normally, chemical additives are added directly to the binder before mixing (Rubio et al., 2012). Besides benefits that WMA can bring such as saving fuel, reducing gases during production, opening the paving window, it is believed that WMA will last longer than HMA (D'Angelo et al., 2008). There have been many studies conducted in laboratories (Lee, Amirkhanian et al. 2009, Hill, Behnia et al. 2012, Topal, Sengoz et al. 2014) to investigate the performance of WMA, the use of WMA was also reported to be successful in practice worldwide (Tutu and Tuffour, 2016).

In 2013, the Arizona Chemical Company released a rejuvenator product called Sylvaroad $^{\mathrm{TM}}$ RP1000. This product is made from crude tall oil and crude sulphate turpentine, pine chemicals produced by the pulp and paper industry (Smith, 2015). The product was developed to increase the ability of adding higher RAP proportion into HMA while still maintaining good performance of asphalt mixtures (Arizona-Chemical, 2013). So far, there have been limited published research articles about this new product although its information can be found on unpublished media such as the company's website. It can be understood that the purpose of using this additive is to rejuvenate RAP in the HMA. The question here is whether this rejuvenator can work in WMA. This research will investigate whether Sylvaroad can work in WMA. For this purpose, the study was carried out to evaluate the performance of WMA using the rejuvenator Sylvaroad. The performance of WMA with Sylvaroad was compared with HMA and one another chosen WMA. Tests were done on moisture resistance, fatigue cracking, rutting and a semi-circular bending test. The semi-circular bending test was chosen to further study the cracking resistance properties of asphalt mixtures.

\section{Materials and Mixture Designs}

\section{Materials}

To prepare specimens for testing, one type of bitumen with penetration grade 80/100, two types of chemical additives, Evotherm $3 \mathrm{G}$ and Sylvaroad were used. Aggregates and bitumen were secured from a local contractor in Christchurch, New Zealand. Evotherm and Sylvaroad are used to enhance coating and workability of mixtures at lower production temperatures than HMA. Both of the two additives are in liquid form. In this research, both Evotherm and Sylvaroad were directly added to the heated binder before mixing. The addition percentages 
of Evotherm and Sylvaroad were $0.5 \%$ and $2 \%$ by the mass of the total binder, respectively. The dosages of the additives were chosen based on the recommendations of additive manufacturers.

\section{Mixture Designs}

The mixture design was carried out for both HMA and WMA. New Zealand standard AC 10 dense graded asphalt mixture was used in this research. The AC 10 is a dense graded mixture with a maximum nominal aggregate size of $10 \mathrm{~mm}$. For HMA, the mixing and compacting temperatures were same at $142^{\circ} \mathrm{C}$ according to the AS/NZS 2891.2.1:2014 (AS/NZS, 2014) and AS/NZS 2891.2.2:2014 (AS/NZS, 2014). The two WMA mixtures were mixed and compacted at $115^{\circ} \mathrm{C}$ and $110^{\circ} \mathrm{C}$ respectively. The aggregate gradations for both WMA and HMA were maintained the same as shown in Figure 1.

Figure 1. Aggregate Gradation Curve of HMA and WMA

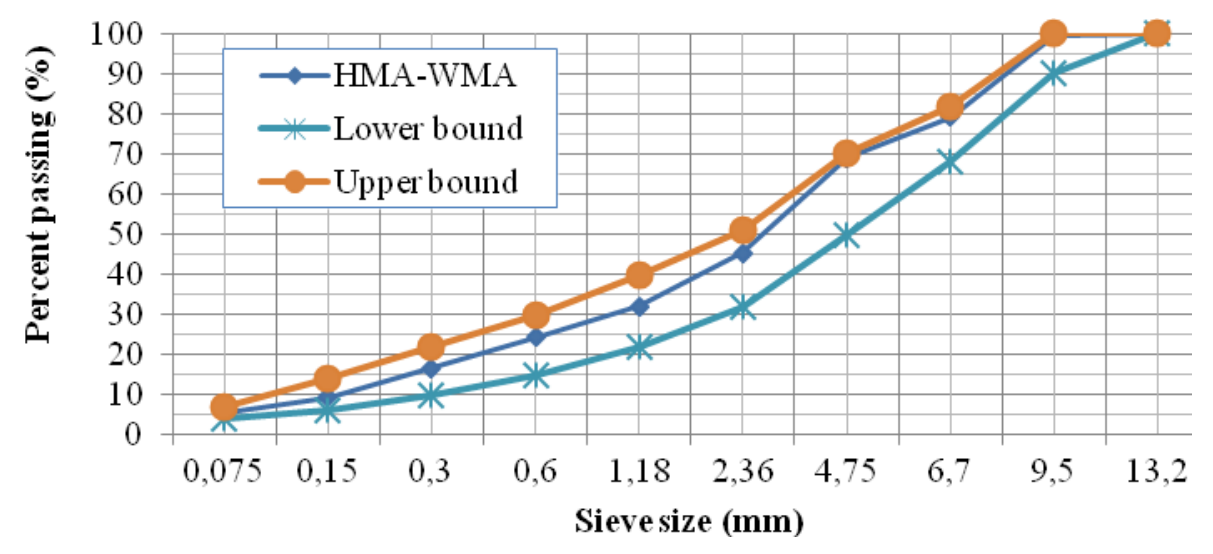

The gyratory compactor was used to compact the asphalt mixture specimens in this study. All asphalt mixture specimens for the mixure design purpose were prepared with a height of $85 \mathrm{~mm}$ and a diameter of $150 \mathrm{~mm}$. According to the AS/NZS 2891.2.2:2014 (AS/NZS, 2014) standard, the ram pressure was $240 \mathrm{kPa}$; and the gyration angle was maintained at $3^{\circ}$. For New Zealand and Australian standards, the ram pressure of $240 \mathrm{kPa}$ is much less than the $600 \mathrm{kPa}$ recommended by Superpave. However, the angle of gyration for New Zealand and Australian standards is $3^{\circ}$, which is much larger than the angle of gyration of $1.25^{\circ}$ recommended by the Superpave. The larger angle of gyration compensates for the low ram pressure. The difference in compaction for different levels of traffic is the number of gyrations, which is specified in "Specification for dense graded and stone mastic asphalts - NZTA M10: 2014" (NZTA 2014). In this study, the gyration number of 120 was chosen for heavy traffic.

Optimum binder contents were chosen at the target air void of $4 \%$. To achieve that, for each mixture, there were 15 specimens were prepared at 5 different binder contents. Thus for each binder content there were three replicas produced. The volumetric properties of each specimen was measured and the optimum binder content was determined which corresponds to $4 \%$ air voids. 
In the case of WMA, optimum binder contents were firstly designed for mixtures with Evotherm. As this study primarily concentrate on the effect of additives on the mechanical performance of WMA rather than the compatibility, the optimum binder contents for Evotherm mixture was adopted for mixture with Sylvaroad. The optimum binder contents of HMA and WMA were 5.1\% and $4.8 \%$ by mixture mass, respectively.

\section{Experiments}

This part demonstrates the experimental tests in this study, including moisture resistance test, fatigue cracking, rutting resistance test, and a semi-circular bending test. For each type of test, the methodology, result, and discussion are presented.

\section{Moisture Resistance Test}

The moisture resistance test was carried out according to the AG:PT/T232 (AG:PT/T232 2007) to investigate the moisture susceptibility of the mixes. Cylindrical specimens were produced with a diameter of $150 \mathrm{~mm}$ and a height of $85 \mathrm{~mm}$. All the test specimens had the air voids in a range of $8.0 \pm 1.0 \%$. The test results were evaluated based on the tensile strength ratio (TSR) of each asphalt mixture. The TSR is the ratio of the average indirect tensile strength (ITS) of specimens in wet condition to the average ITS of specimens in dry condition. To determine the TSR values, six specimens were produced for each asphalt mixture, 3 specimens for the dry subset and other 3 specimens for the wet subset. These specimens were subjected to ITS test. For dry specimens, they were conditioned in a temperature control chamber at $25^{\circ} \mathrm{C}$ for 2 hours before testing. For wet specimens, firstly they were saturated in a vacuum at $50^{\circ} \mathrm{C}$ to achieve $55-80 \%$ saturation degree. After that, they were conditioned in water at $60^{\circ} \mathrm{C}$ for 24 hours. Finally, the specimens were conditioned in water at $25^{\circ} \mathrm{C}$ for 2 hours before testing. TSR values of $80 \%$ or greater are recommended for the moisture resistance of asphalt mixtures.

\section{Fatigue Cracking Test}

The four-point bending beam test was utilized to investigate the fatigue resistance of the asphalt mixtures. Specimens dimension and test setup were prepared according to the AG:PT/T233 "Fatigue life of compacted bituminous mixes subject to repeated flexural bending"(AG:PT/T233 2006). Compacted slabs with a dimension of $305 \times 405 \times 75 \mathrm{~mm}$ were cut into beams, which were $50 \mathrm{~mm}$ high, $65 \mathrm{~mm}$ wide and $405 \mathrm{~mm}$ long. The air void target for test specimens was $7 \pm 0.5 \%$. There were 3 specimens produced and tested for each asphalt mixture. Constant displacement mode with sinusoidal load wave form with frequency 10 $\mathrm{Hz}$, and maximum strain amplitude of 400 micro-strains were applied to all specimens. The specimens were maintained in a temperature-control chamber for 
2 hours before testing. Fatigue life was determined as the number of cycles at which the stiffness of the asphalt mixture degrades to $50 \%$ of the initial flexural stiffness.

\section{Rutting Test}

In this study, rutting resistance evaluation was carried out by using the wheeltracking test apparatus. The test was conducted according to the AG:PT/T231 "Deformation resistance of asphalt mixtures by the wheel tracking test" (AG:PT/T231, 2006). Slab specimens were prepared with dimensions of $305 \mathrm{x}$ $305 \times 50 \mathrm{~mm}$. During the test, the slab was restrained at two ends of the travel direction of the wheel, while the slab was free to move laterally. At least two replicates are required for the test by the standard. The air voids are required to be in a range of $5 \pm 1 \%$. To carry out the test, the specimens were conditioned in a temperature-control chamber for 7 hours to make sure that the slabs reached a constant temperature of $60^{\circ} \mathrm{C}$. After conditioning, the test was started at the same temperature. During the test, the rut depth and the corresponding number of cycle were recorded. The test terminated when the rut depth reached $15 \mathrm{~mm}$ or the number of cycle reached 100,000 whichever occurred first. For the rutting test in this study, there were 2 specimens produced and tested for HMA and WMASylvaroad, and 3 specimens were tested in the case of WMA-Evotherm.

\section{Semi-circular Bending Test}

In this research, the semi-circular bending ( $\mathrm{SCB}$ ) test was conducted to evaluate the cracking resistance of asphalt mixtures under a monotonic loading. There are two phases in a cracking failure: crack initiation and crack propagation (Huang et al., 2013). Because cracking failures greatly affect the ride quality and long-term performance of the pavement, therefore, in-depth understanding of the cracking mechanism is vital for the pavement design (Lancaster et al., 2013). Among tests used to investigate cracking resistance of the asphalt mixture, the SCB test has been developed and widely used. The test was originally developed for determining the fracture resistance in rock mechanics (Huang et al., 2013), and has been successfully used to analyse the fracture properties of asphalt mixtures (Molenaar et al., 2002). The SCB test is gradually gaining more attention from researchers and engineers due to its simplicity, repeatability and consistency in investigating cracking characteristics of asphalt mixtures (Saha and Biligiri, 2015).

To prepare samples for this test, cylindrical specimens with a height of 177 $\mathrm{mm}$ and a diameter of $150 \mathrm{~mm}$ were produced. These specimens were cored and trimmed into cylindrical specimens with $100 \mathrm{~mm}$ in diameter and $30 \pm 1 \mathrm{~mm}$ in height. Cylindrical specimens with a height of $30 \mathrm{~mm}$ were cut into two halves and notched to create specimens for the semi-circular tests. Four notch dimensions were investigated in this study: 5, 10, 15 and $20 \mathrm{~mm}$ with a gap thickness of 2 $\mathrm{mm}$. Specimens for the semi-circular test have an air void target of $5 \pm 1 \%$. Before testing, specimens were conditioned in a temperature-control chamber for 
2 hours to reach an equilibrium temperature of $25^{\circ} \mathrm{C}$. After that, they were subjected to a monotonic load with the rate chosen at $1 \mathrm{~mm} / \mathrm{min}$. The span between to the two steel supports was $80 \mathrm{~mm}$, approximately $0.8 \mathrm{~d}$, in which $\mathrm{d}$ is the diameter of the specimen. Three replicates were prepared for each asphalt mixture at each notch depth. In total, 36 samples were created for the SCB test.

\section{Results and Analysis}

\section{Moisture Resistance Test}

The test results from the moisture resistance test of HMA and WMA are shown in Table 1 and Figure 2. From Table 1, it can be seen that the results had high consistency with the coefficient of variation values were quite low for mixtures, in both dry and wet conditions. In the dry condition, HMA had the highest ITS value. WMA-Evotherm occupied the second highest ITS and was about $15 \%$ lower than the control HMA. The mixture with Sylvaroad showed the lowest ITS value, approximately 40\% smaller compared to that of HMA. The results indicate that compared to HMA, WMA mixtures were softer, which might be due to the reduction in mixing temperature and the addition of additives.

In the wet condition, the ITS of HMA reduced greatly compared to the dry condition. The tensile strength ratio (TSR) of HMA between wet and dry condition was $46 \%$. In the case of WMA, the addition of Evotherm considerably improved the moisture resistance of the mixture compared to HMA. The ITS of WMA-Evotherm in wet condition was much higher than that of HMA in the same condition, approximately 65\%. The TSR of WMA-Evotherm was relatively high, about $91 \%$, showing that the mixture passed the acceptance level of $80 \%$ of the moisture resistance test. Whereas, the addition of Sylvaroad seemed not to affect much the moisture resistance of the mixture, as the ITS of the mixture in wet condition reduced greatly compared to the dry condition, and the TSR was about $36 \%$. In this study, the TSR values of HMA and WMA-Sylvaroad were much lower than the expected value of $80 \%$. However, the TSR values of HMA and WMA-Sylvaroad are still meaningful as they indicate the effect of the new additive to the water resistance of WMA. Visual observation was also carried out and it showed considerable stripping in the cases of HMA and WMA-Sylvaroad, in which the later mixture showed the most severe stripping as shown in Figure 3 while WMA-Evotherm has not visually shown any stripping.

Table 1. Experimental Results of Mixtures for Moisture Resistance Test

\begin{tabular}{|l|l|l|l|l|l|}
\hline Mixture & Subset & Mean ITS (kPa) & S.D. & CoV (\%) & TSR (\%) \\
\hline \multirow{2}{*}{ HMA } & Dry & 633.4 & 35.1 & 5.5 & \multirow{2}{*}{45.8} \\
\cline { 2 - 5 } & Wet & 290.0 & 21.1 & 7.3 & \multirow{2}{*}{91.3} \\
\hline \multirow{2}{*}{ WMA-E } & Dry & 527.2 & 25.8 & 4.9 & \multirow{2}{*}{35.8} \\
\cline { 2 - 5 } & Wet & 481.3 & 9.1 & 1.9 & \\
\hline \multirow{2}{*}{ WMA-S } & Dry & 412.7 & 15.5 & 3.8 & \\
\cline { 2 - 5 } & Wet & 147.9 & 6.3 & 4.2 & \multicolumn{2}{|l}{} \\
\hline
\end{tabular}


Figure 2. Moisture Resistance Test Results

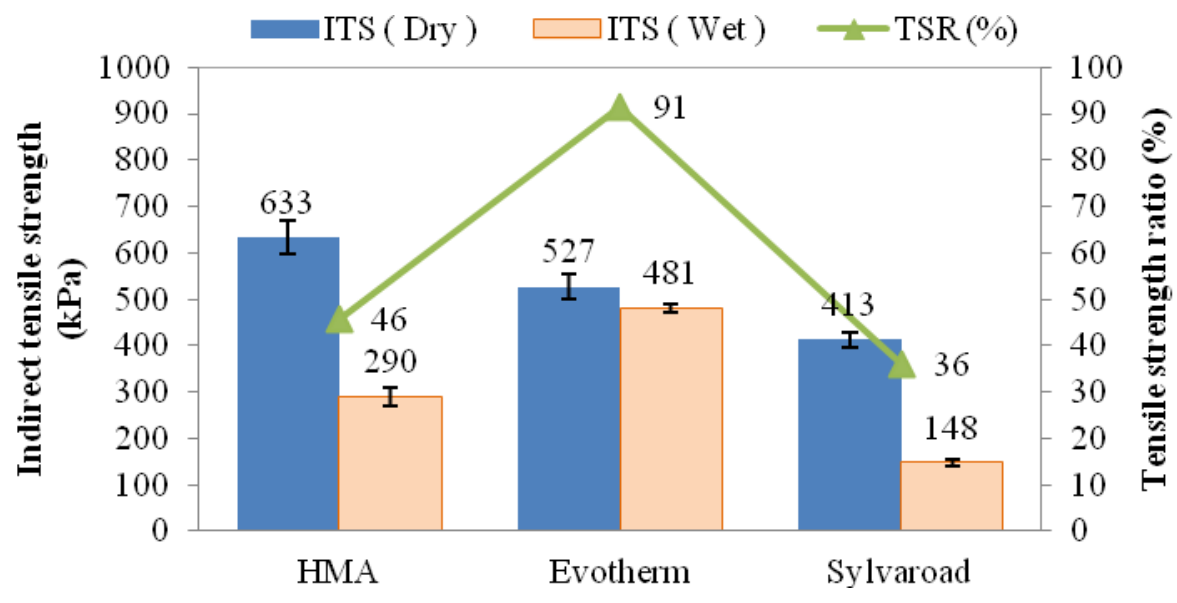

Figure 3. Investigation of Stripping of Wet Subset Samples after Testing. a) HMA; b) WMA-Evotherm; c) WMA-Sylvaroad
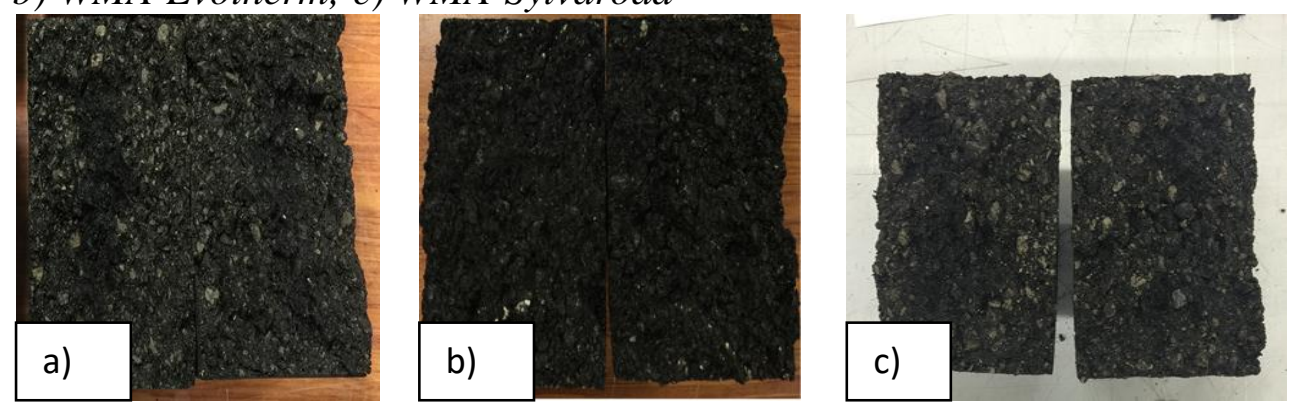

\section{Fatigue Cracking Test}

The fatigue test results, including the number of cycles to fatigue failure and the initial stiffness of mixtures, as well as standard deviations and coefficients of variation were described in Table 2 and Figure 4. It can be seen that, the results of the initial stiffness had quite high consistency via the relatively low $\mathrm{CoV}$ values (Table 3). The CoV values in the case of fatigue life were also quite low, except the case of WMA-Sylvaroad, which had a slightly large $\mathrm{CoV}$ value.

From Figure 4, it is observed that the WMA-Sylvaroad performed best with regard to fatigue resistance as it shows the highest fatigue life. The mixture had fatigue life approximately 50\% higher than the control HMA. WMA-Evotherm had the lowest fatigue life, roughly 3 times smaller than HMA. The results also showed that HMA was still the stiffest mixture, following by the WMA-Evotherm and WMA-Sylvaroad mixture had the smallest flexural stiffness. The results of flexural stiffness indicate that Sylvaroad seems to improve fatigue resistance of WMA better than Evotherm. 
Table 2. Experimental Results of All Mixtures for Fatigue and Rutting Tests

\begin{tabular}{|l|l|l|l|l|l|l|l|l|l|}
\hline \multirow{2}{*}{ Mixture } & \multicolumn{3}{|l|}{ Initial stiffness (MPa) } & \multicolumn{3}{|l|}{ Fatigue life (cycle) } & \multicolumn{3}{l|}{ Rutting (cycle) } \\
\cline { 2 - 10 } & Mean & S.D. & $\begin{array}{l}\text { CoV } \\
(\%)\end{array}$ & Mean & S.D. & $\begin{array}{l}\text { CoV } \\
(\%)\end{array}$ & Mean & S.D. & $\begin{array}{l}\text { CoV } \\
(\%)\end{array}$ \\
\hline HMA & 3282 & 123.9 & 3.8 & 580013 & 46494 & 8 & 2922 & 696 & 24 \\
\hline $\begin{array}{l}\text { WMA- } \\
\text { E }\end{array}$ & 3107 & 136.7 & 4.4 & 205107 & 26118 & 12.7 & 1401 & 395 & 28 \\
\hline $\begin{array}{l}\text { WMA- } \\
\text { S }\end{array}$ & 2527 & 34.8 & 1.4 & 881920 & 310552 & 35.2 & 1126 & 195 & 17 \\
\hline
\end{tabular}

Figure 4. Fatigue Test Results

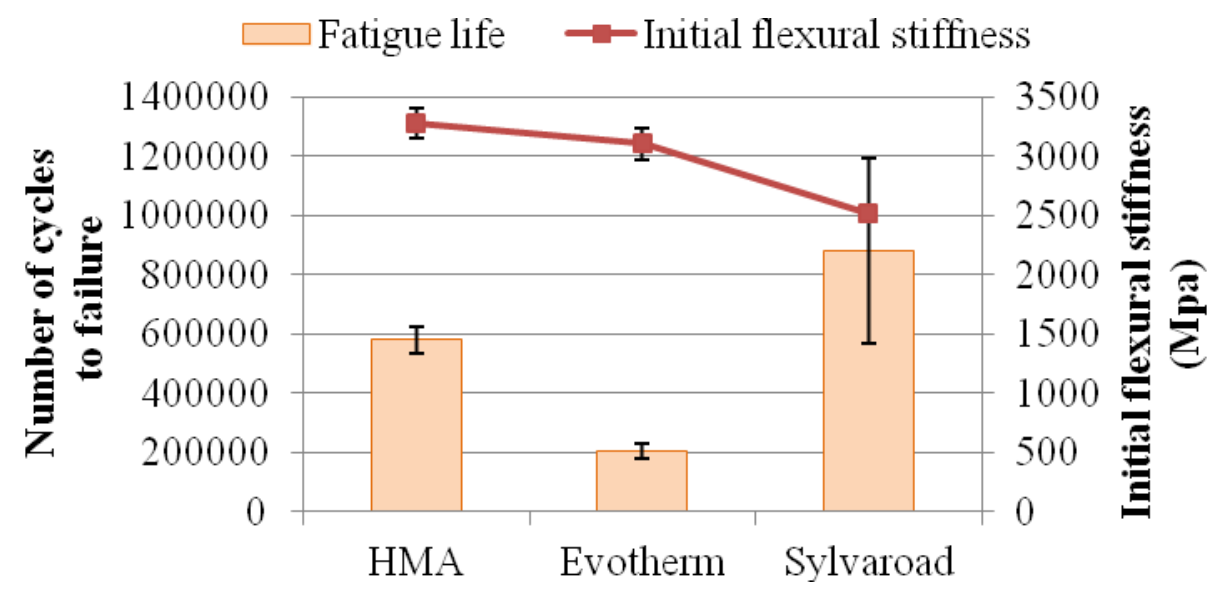

\section{Rutting Test}

The results from the wheel tracking test are exhibited in Table 2 and Figure 5. Results from Table 2 show that the three mixtures had quite similar values of $\mathrm{CoV}$, and a little bit high (from 17 to $28 \%$ ) compared to other tests. From Figure 5 it can be seen that the HMA performed the best among the asphalt mixtures. The number of cycles to reach the maximum rut depth of HMA was as twice as that of WMA-Evotherm. It was again the mixture with Sylvaroad showed to be the softest mixture, as the mixture performed the worse in the rutting test. The results may cause a concern about the rutting resistance of WMA mixtures compared to HMA. The results also indicate that the binder in WMA was softer than HMA due to the lower producing temperatures and due to the addition of additives. It is believed that the used additives might have not only helped mixing at lower temperatures than HMA, but also made the binder in compacted asphalt mixtures softer. The argument for that is if the additives had not softened the mixtures, the rutting resistance of WMA with Sylvaroad and Evotherm would have been similar regardless of different additive types and dosages, as they were produced by using the same mixture design. 
Figure 5. Rutting Test Results

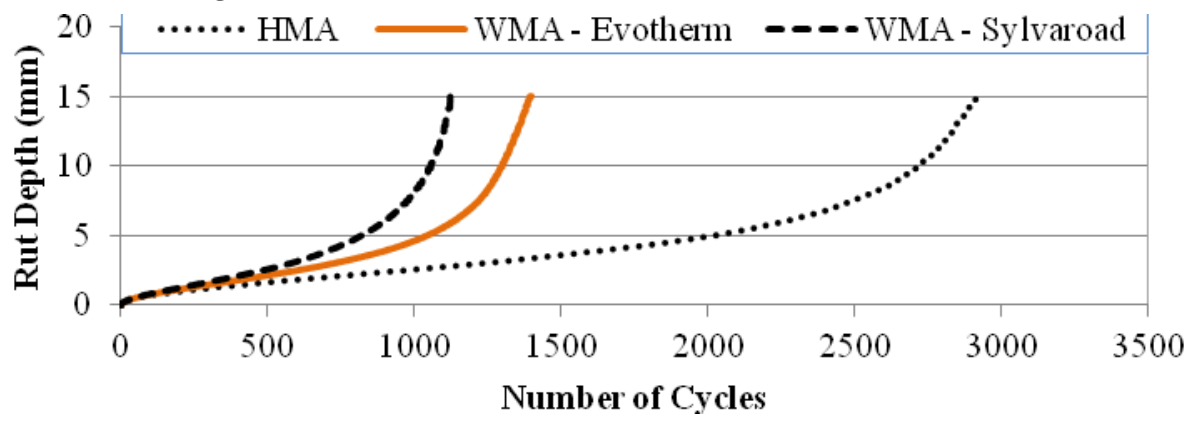

\section{Semi-circular Bending Test}

The typical test result from the SCB test is shown in Figure 6. When a load is applied on the sample, the loading value increases quickly while the displacement increases more slowly until the load value reaches the peak value. This is called the pre-cracking phase. After the peak load reached, the crack occurs and the displacement increases with a quicker speed than before while the load applied reduces with a slower speed. This phase is called post-cracking. In this study, three parameters from the SCB test are presented. They are fracture energy of the pre-cracking phase, tensile strength, and vertical strain at maximum load.

The fracture energy of the specimen derived from the semi-circular test was calculated as per Equation 1:

$G_{f}=1000 \times \frac{W_{f}}{H \times L}$

Where:

$\mathrm{G}_{\mathrm{f}}=$ Fracture energy, $\mathrm{J} / \mathrm{m}^{2}$

$\mathrm{W}_{\mathrm{f}}=$ Fracture work, N.mm, the area between the load curve and the load line displacement;

$\mathrm{H}=$ Thickness of sample, $\mathrm{mm}$;

$\mathrm{L}=$ Ligament length, $\mathrm{mm}$.

The maximum stress at the bottom of the specimen derived from the semicircular test was calculated as per Equation 2 (Molenaar et al., 2002; Arabani and Ferdowsi, 2009):

$\sigma_{m}=3564 \frac{P}{D \times H}$

Where:

$\sigma_{\mathrm{m}}=$ Maximum stress, $\mathrm{kPa}$;

$\mathrm{P}=$ Peak load, $\mathrm{N}$;

$\mathrm{D}=$ Diameter of sample, $\mathrm{mm}$. 
Figure 6. Typical Test Results

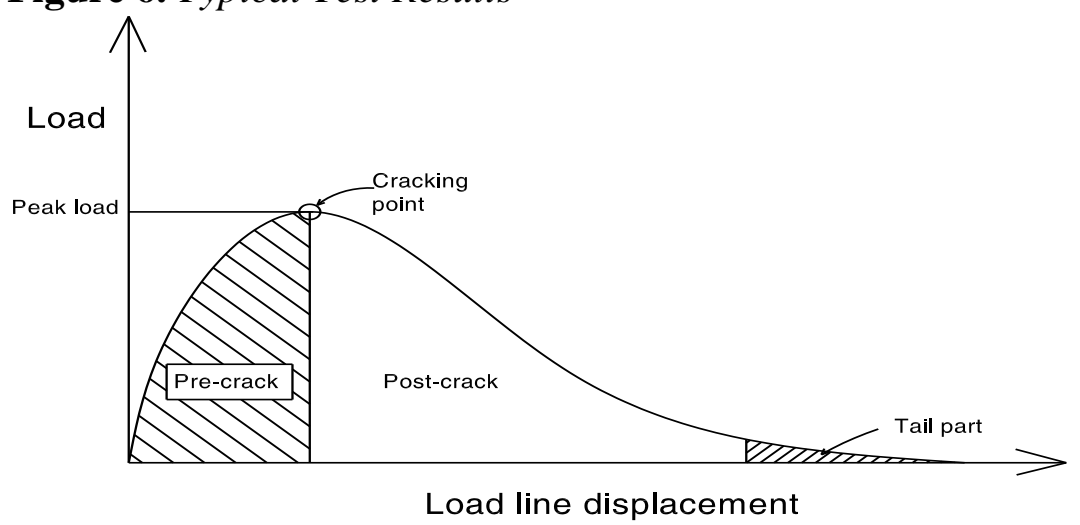

The vertical strain at maximum load was calculated as per Equation 3:

$\varepsilon_{m}=\frac{\Delta w}{W}$

Where:

$\varepsilon_{\mathrm{m}}=$ Vertical strain at maximum load;

$\Delta \mathrm{w}=$ Load line displacement at maximum load, $\mathrm{mm}$;

$\mathrm{W}=$ High of SCB sample, $\mathrm{mm}$.

The results from the SCB tests are presented in Table 3 and Figures 7, 8, and 9. The SCB test results had a high consistency; most of the CoV values were lower than $10 \%$. There was just one case with a $\mathrm{CoV}$ value higher than $25 \%$, which fell in the case of the fracture energy. CoV values lower than $25 \%$ can be seen to satisfy the repeatability of this kind of test ( $\mathrm{Li}$ and Marasteanu, 2010). In the case of fracture energy, HMA showed higher values than WMA mixtures at all notch depths. This indicates that HMA had greater resistance to fracture than others mixtures. The results were also quite consistent, in which WMA-Evotherm had smaller fracture energies than HMA, but larger values than WMA-Sylvaroad at four notch depths. This shows that the WMA-Sylvaroad has worse fracture resistance than WMA-Evotherm.

In terms of tensile strength, the results from SCB test exhibits a similar trend with the results in the moisture resistance test, in dry condition, in which the tensile strengths of HMA were the highest among mixtures regardless of notch depth. Furthermore, the tensile strength values of WMA-Evotherm were again lower than HMA, but greater than WMA-Sylvaroad at each notch depth. However, in the case of strain, there was no clear trend as in the cases of fracture energy and tensile strength. The strain reduced with the increase of the notch depth. However, at each notch depth, the strains of the three mixtures were relatively similar, and there was no clear trend observed on the whole range of notch depths. 
Table 3. Experimental Results of All Mixtures for SCB Tests

\begin{tabular}{|c|c|c|c|c|c|c|c|c|c|}
\hline \multirow[b]{2}{*}{ Mixture } & \multicolumn{3}{|l|}{ HMA } & \multicolumn{3}{|c|}{ WMA-E } & \multicolumn{3}{|c|}{ WMA-S } \\
\hline & $\begin{array}{l}\mathrm{G}_{\mathrm{f}} \\
\left(\mathrm{J} / \mathrm{m}^{2}\right)\end{array}$ & $\begin{array}{l}\sigma_{\mathrm{m}} \\
(\mathrm{kPa})\end{array}$ & $\begin{array}{l}\varepsilon_{\max } \\
(\%)\end{array}$ & $\begin{array}{l}\mathrm{G}_{\mathrm{f}} \\
\left(\mathrm{J} / \mathrm{m}^{2}\right)\end{array}$ & $\begin{array}{l}\sigma_{\mathrm{m}} \\
(\mathrm{kPa})\end{array}$ & $\begin{array}{l}\varepsilon_{\max } \\
(\%)\end{array}$ & $\begin{array}{l}\mathrm{G}_{\mathrm{f}} \\
\left(\mathrm{J} / \mathrm{m}^{2}\right)\end{array}$ & $\begin{array}{l}\sigma_{\mathrm{m}} \\
(\mathrm{kPa})\end{array}$ & $\begin{array}{l}\varepsilon_{\max } \\
(\%)\end{array}$ \\
\hline & \multicolumn{9}{|c|}{ Notch length $-5 \mathrm{~mm}$} \\
\hline Mean & 197.7 & 447.5 & 0.0382 & 178.8 & 374.8 & 0.0406 & 106.4 & 237.2 & 0.0380 \\
\hline S.D. & 22.4 & 46.1 & 0.0008 & 11.5 & 23.5 & 0.0029 & 22.1 & 18.4 & 0.0040 \\
\hline \multirow[t]{2}{*}{$\operatorname{CoV}(\%)$} & 11.3 & 10.3 & 2.0 & 6.5 & 6.3 & 7.1 & 20.8 & 7.8 & 10.6 \\
\hline & \multicolumn{9}{|c|}{ Notch length $-10 \mathrm{~mm}$} \\
\hline Mean & 165.7 & 345.5 & 0.0357 & 124.4 & 259.0 & 0.0343 & 83.0 & 177.2 & 0.0339 \\
\hline S.D. & 6.8 & 14.7 & 0.0038 & 29.8 & 7.6 & 0.0068 & 22.2 & 11.7 & 0.0077 \\
\hline \multirow[t]{2}{*}{$\mathrm{CV}(\%)$} & 4.1 & 4.3 & 10.7 & 23.9 & 3.0 & 19.9 & 26.7 & 6.6 & 22.7 \\
\hline & \multicolumn{9}{|c|}{ Notch length $-15 \mathrm{~mm}$} \\
\hline Ave. & 149.5 & 273.1 & 0.0322 & 95.2 & 203.9 & 0.0289 & 70.2 & 143.7 & 0.0319 \\
\hline SD & 6.9 & 25.8 & 0.0023 & 5.6 & 7.8 & 0.0016 & 15.8 & 21.6 & 0.0020 \\
\hline \multirow[t]{2}{*}{$\operatorname{CoV}(\%)$} & 4.6 & 9.4 & 7.2 & 5.9 & 3.8 & 5.5 & 22.5 & 15.0 & 6.3 \\
\hline & \multicolumn{9}{|c|}{ Notch length $-20 \mathrm{~mm}$} \\
\hline Mean & 95.4 & 165.1 & 0.0285 & 88.5 & 153.2 & 0.0299 & 60.4 & 99.4 & 0.0294 \\
\hline S.D. & 1.4 & 9.8 & 0.0010 & 13.3 & 13.8 & 0.0026 & 9.0 & 7.6 & 0.0031 \\
\hline $\operatorname{CoV}(\%)$ & 1.5 & 6.0 & 3.6 & 15.0 & 9.0 & 8.8 & 14.8 & 7.6 & 10.7 \\
\hline
\end{tabular}

Figure 7. Pre-cracking Fracture Energy Results

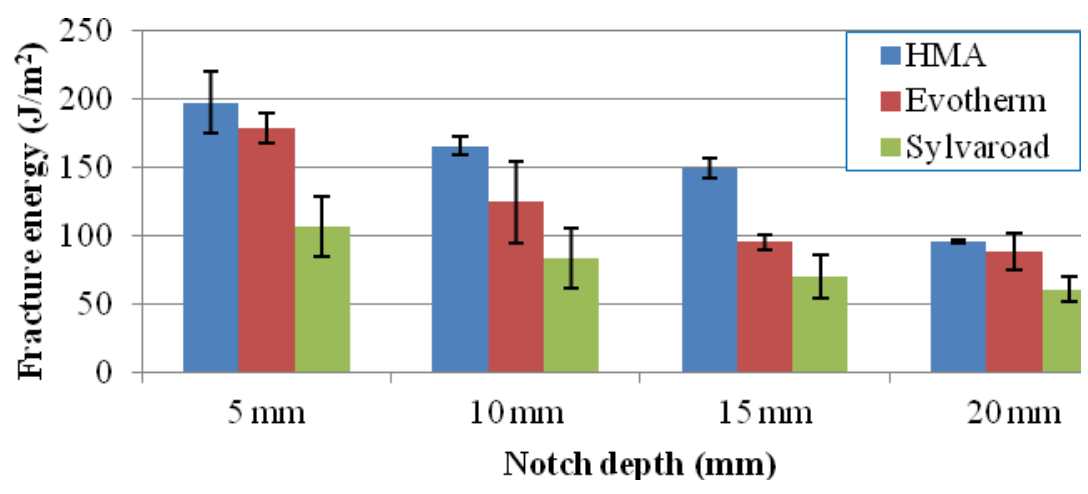

Figure 8. Tensile Strength Results

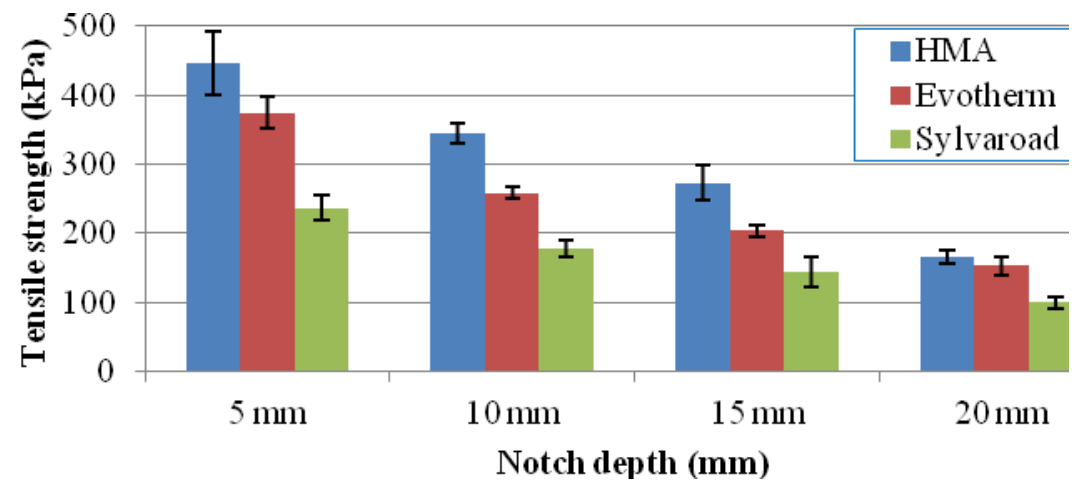


Figure 9. Strain Results

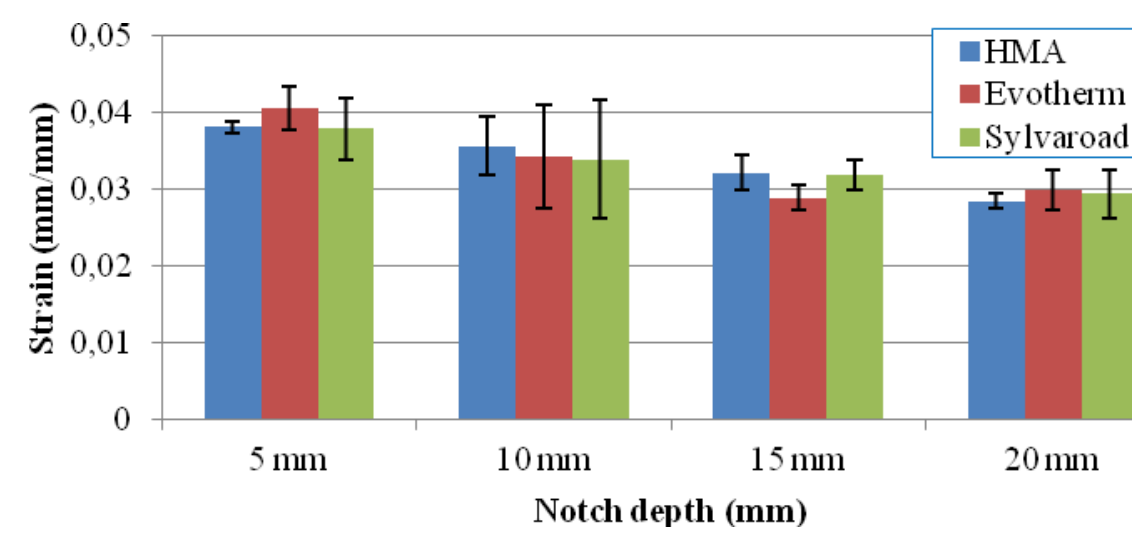

\section{Conclusions}

This study mainly evaluated the performance of Sylvaroad as a warm mix asphalt additive. The performance of the asphalt mixture with Sylvaroad was compared with the mixture produced with Evotherm and HMA, which worked as a control mixture. Experiments were carried out at the Transportation Laboratory, University of Canterbury. Based on the results obtained from the laboratory prepared asphalt mixtures, the following conclusions have been made:

- Evotherm improved the moisture resistance of the asphalt mixture, while Sylvaroad had a negligible effect on the moisture resistance of the asphalt mixture.

- The addition of additives and the reduction in mixing temperature made the WMA softer than the HMA. Both WMA with Evotherm and Sylvaroad showed lower tensile strength, flexural stiffness, and rutting resistance than the control HMA.

- Sylvaroad helped improve the fatigue cracking resistance of the mixture. The WMA-Sylvaroad had the highest fatigue life based on the four-point bending beam test.

- The semi-circular bending test is a promising test method. The tensile strength that results from the semi-circular test had a similar trend with the indirect tensile test method.

- Fracture energies of Sylvaroad and Evotherm mixtures were smaller than HMA, indicating that the two WMA had a lower fracture resistance than HMA. Among the three asphalt mixtures, WMA-Sylvaroad showed the worse in fracture resistance.

- Strain values in the semi-circular bending tests were very similar and there was no clear trend observed.

- The study indicates that Sylvaroad can be a promising additive used in WMA with high content of reclaimed asphalt pavement. 


\section{Acknowledgments}

The authors gratefully acknowledge the staff from Fulton Hogan for their help during this research. The authors also gratefully acknowledge Damien Hond and Arizona Chemical for additives donation. The authors thank John Kooloos, the technician of the Transportation lab, University of Canterbury for his kind help during this study. The authors thank the Civil and Natural Resources Engineering department for financial sponsor, giving the authors a valuable chance to present this study at the conference.

\section{References}

AG:PT/T231 (2006). "Deformation resistance of asphalt mixtures by the wheel tracking test." Austroads Manual of Test Methods.

AG:PT/T233 (2006). "Fatigue life of compacted bituminous mixes subject to repeated flexural bending." Austroads Manual of Test Methods.

AG:PT/T232 (2007). "Stripping potential of asphalt - Tensile strength ratio." Austroads Manual of Test Methods.

Arabani, M. and B. Ferdowsi (2009). "Evaluating the semi-circular bending test for HMA mixtures." International Journal of Engineering A: Basics 22(1): 47-58.

Arizona-Chemical (2013). "SYLVAROADTM RP1000 Performance Additive [Brochure]."

AS/NZS (2014). Standard 2891.2.1:2014, Methods of sampling and testing asphalt. Part 1: Sample preparation - Mixing, quatering and conditioning of asphalt in the laboratory, Australian/New Zealand Standard.

AS/NZS (2014). Standard 2891.2.2:2014, Methods of sampling and testing asphalt. Part 2: Sample preparation - Compaction of asphalt test specimens using a gyratory compactor, Australian/New Zealand Standard.

Capitão, S., L. Picado-Santos and F. Martinho (2012). "Pavement engineering materials: Review on the use of warm-mix asphalt." Construction and Building Materials 36: 1016-1024.

D'Angelo, J. A., E. E. Harm, J. C. Bartoszek, G. L. Baumgardner, M. R. Corrigan, J. E. Cowsert, T. P. Harman, M. Jamshidi, H. W. Jones and D. E. Newcomb (2008). Warm-mix asphalt: European practice. Report No. FHWA-PL-08-007. Available from http://international.fhwa.dot.gov/pubs/p108007/.

Hill, B., B. Behnia, S. Hakimzadeh, W. Buttlar and H. Reis (2012). "Evaluation of lowtemperature cracking performance of warm-mix asphalt mixtures." Transportation Research Record: Journal of the Transportation Research Board (2294): 81-88.

Huang, B., X. Shu and G. Zuo (2013). "Using notched semi circular bending fatigue test to characterize fracture resistance of asphalt mixtures." Engineering Fracture Mechanics 109: 78-88.

Lancaster, I., H. Khalid and I. Kougioumtzoglou (2013). "Extended FEM modelling of crack propagation using the semi-circular bending test." Construction and Building Materials 48: 270-277.

Larsen, O. (2001). "Warm Asphalt Mix with Foam-WAM Foam." IRF 2001 Partie B: Thèmes Techniques: 00469.

Lee, S.-J., S. N. Amirkhanian, N.-W. Park and K. W. Kim (2009). "Characterization of warm mix asphalt binders containing artificially long-term aged binders." Construction and Building Materials 23(6): 2371-2379. 
Leng, Z., A. Gamez and I. L. Al-Qadi (2013). "Mechanical property characterization of warm-mix asphalt prepared with chemical additives." Journal of Materials in Civil Engineering 26(2): 304-311.

Li, X.-J. and M. Marasteanu (2010). "Using semi circular bending test to evaluate low temperature fracture resistance for asphalt concrete." Experimental mechanics 50(7): 867-876.

Molenaar, A., A. Scarpas, X. Liu and S. Erkens (2002). "Semi-circular bending test; simple but useful?" Journal of the Association of Asphalt Paving Technologists 71.

NZTA, N. Z. T. A. (2014). "SP/SM10:140905 Specification for Dense Graded and Stone Mastic Asphalts. Available at http://bit.ly/2f3htX1"

Rubio, M. C., G. Martínez, L. Baena and F. Moreno (2012). "Warm mix asphalt: an overview." Journal of Cleaner Production 24: 76-84.

Saha, G. and K. P. Biligiri (2015). "Fracture damage evaluation of asphalt mixtures using Semi-Circular Bending test based on fracture energy approach." Engineering Fracture Mechanics 142: 154-169.

Smith, K. (2015). "A rejuvenator derived from pine trees and natural asphalt." World Highways, October 2015. http://bit.ly/2fUSgeU.

Topal, A., B. Sengoz, B. V. Kok, M. Yilmaz, P. Aghazadeh Dokandari, J. Oner and D. Kaya (2014). "Evaluation of mixture characteristics of warm mix asphalt involving natural and synthetic zeolite additives." Construction and Building Materials 57: 38-44.

Tutu, K. A. and Y. A. Tuffour (2016). "Warm-Mix Asphalt and Pavement Sustainability: A Review." Open Journal of Civil Engineering 6(02): 84.

Zaumanis, M. (2010). Warm mix asphalt investigation Master thesis, Riga Technical University. Denmark.

Zhang, J. (2010). "Effects of warm-mix asphalt additives on asphalt mixture characteristics and pavement performance." M.Sc. thesis. University of Nebraska Lincoln. Paper 12.(http://digitalcommons.unl.edu/civilengdiss/12). 